\title{
Modelling heat exchange between RCC dam and reservoir
}

\begin{abstract}
Temperature control plays an important role in the design and construction of rollercompacted concrete (RCC) dams. Hydration of cement and climatic changes on the convective boundaries are the two main heat sources of the temperature rise in RCC dams. Therefore, the effects of these two factors have to be determined accurately in order to reduce the risk of thermally induced cracking in these dams. Simplified approaches are usually adopted to approximate the temperature changes on the upstream dam side after the dam reservoir is filled. These simplified approaches are usually based on long-term observations of similar reservoirs. However, it is practically hard to generalise the conditions of these reservoirs with respect to the reservoir under consideration. In this work, the finite-element method has been used to simulate the heat exchange between the RCC dam body and the reservoir water taking into account the reservoir operation. A realistic isothermal profile has been obtained that has been used to determine the cracking probability of the RCC dam body.
\end{abstract}

